\title{
The Comparison of Traditional Gardens Artistic Conception between China and Japan
}

\author{
Zhong $\mathrm{Yi}^{1,2}$, Bohui Wang ${ }^{1,2}$ and Jianfei Dong ${ }^{1,2, a,{ }^{*}}$ \\ ${ }^{1}$ School of Architecture, Harbin Institute of Technology, Harbin 150006, China. \\ ${ }^{2}$ Heilongjiang Cold Region Urban-Rural Human Settlements Science Key Laboratory, Harbin Institute \\ of Technology, Harbin 150006, China \\ adongjianfei999@hotmail.com
}

Keywords: Zen garden; Japanese rock garden; Temple gardens.

\begin{abstract}
Zen is belongs to the Buddhism of mental perception and also great wisdom of seeking natural character by keeping peaceful. Zen lays emphasis on the Magyar and seeks confirmation of wisdom liberation. After the Tang Dynasty, it stepped into a period of great prosperity gradually and played an important role in the Chinese ancient philosophy, literature, art and so on. As a form of art in Chinese culture, gardens are not only influenced by the traditional Confucian rite and music culture but also, in some sense, inherits the pursuit of Zen philosophy and even creates a special type of Zen garden. Zen garden is one type of temple gardens and also an ancient, special and independent garden system, because it's out of range of religious gardens. Although from China, it matured in Japan. The impact performs in regards of Japan life and religious activities. It triggered Japanese tea ceremony and the appreciation of the simple and unadorned style, emphasizing extremely strong self-control. As it were, Zen is the soul of Japanese garden. Japanese rock garden and earth-bare garden, which have the most special Japanese characteristics, are strongly infiltrated by Zen thought. At the same time, the suitable plant landscape expresses the refinements of Zen in a unadorned and simple style.
\end{abstract}

\section{Introduction}

Zen was created in the Sui and Tang Dynasties and spread into Japan during the Song and Yuan. It stresses penetrating man's disposition through the way of Zen cultivating. Zen master kept looking into the nature for countless times and ultimately understood the origin, which shows that to recognize something through Zen means to achieve near-intuitive response by perceiving it continuously. Though both originating from the basic thoughts of Sixth Patriarch Hui Neng, literati garden and Japanese rock garden, the representatives of Chinese and Japanese garden respectively, have difference in garden creating methods and attitudes, which results in different aesthetic concepts. The comparison and analysis of the Zen gardens between two countries will reveal the culture differences, helping us realize the importance of the landscape design culture background.

\section{Landscape Features of Chinese and Japanese gardens}

2.1 The Comparison of Relevance of Zen"S Ideology between Chinese and Japanese Gardens

To some extent, Chinese and Japanese gardens are deeply in pursuit of Zen's aesthetics." Chinese garden was created in the Shang and Zhou Dynasties, developed in the Tang and Song and finally boomed in the Ming and Qing." The Chinese Zen garden discussed in this article refers to the gardens which were constructed with proven technique during the Ming and Qing dynasties. "The low privacy is in the wild, the middle in the city, and the high in the imperial court." The Chinese classical gardens, especially private gardens, are the spiritual destination for many politicians and literati who yearn for the nature. The original purpose of garden owner is to have spiritual ballast in the world of clamour, and garden itself is the aesthetic outcome with material and spiritual function, whose style is austere and delicate and stands for the taste of the literati. However, the true Zen gardens mean monastery gardens, including some ancestral temples, such as Erwang Temple, Du Fu's Thatched Cottage. 
Basically. Even though private garden and temple garden belong to different categories, they have the same significance of Zen, since Buddhism and Taoism confound with each other, while Buddhism occupied an important status during the Ming and Qing..

Zen believes that "man is a part of Brahmaloka", and demands that man should cultivate himself by thinking and sudden enlightenment. The denomination guides the insular literati to create a place where they can seek for privacy and meditation and find eternity merely on a rock, a plant or a bird. Take Lion Grove Garden for example: In the world of Buddhism, lion is regarded as mythical creatures, so Buddha is called" the lion among man", and when he is sermoning, "the lion is roaring", and Zen garden is also called "grove". Therefore, the name Lion Grove Garden has Zen quality. In addition, the function of layout of rockeries, trees and plaques in the gardens show the essence of Zen, where man can feel "carefree and leisurely", and achieve the level "my heart is Buddha, and Buddha is my heart".(see Fig. 1)

Japan and China separate only by a narrow strip of water, and the former Buddhism roots in the latter. However, when assimilating Chinese culture, Japan ameliorates it continually in the light of local environment. In the meantime, the landscape of Japanese garden evolved from Chinese style, into Ikema Island and Japanese rock garden. Though deeply influenced by Zen's ideology, both are presenting entire difference in aesthetic interest.

The Japanese rock garden in Kyoto ranks the first place of Japanese garden art, "a plant is a world, a wood a life, a grass a paradise, a leaf a Buddha, a sand a pleasure, a site a Pure Land, a smile a destiny, a saying a peace." It's the general survey of Zen's artistic conception. It stipulates in Zaoyuanji, "Rocks and white sand are constructed where there is no water, then Japanese rock garden forms So called Japanese rock garden is that isolated villa, rolling mountains and countryside take shape by placement of rocks." Scenery like white sand ripple can be endued with meaning through association, its beauty needs to be constructed spiritually, thus forming the characteristics like simplicity, nobility, nature and freedom from vulgarity. Compared with Chinese gardens which have more secularity, Japanese rock garden is more like a Shanshui Painting and creates a three-dimensional world in two-dimensional space. With its abstract and pure image, it makes room for people to cultivate themselves. Getting natural pleasure from intangible landscape, is the very essence of Zen thought in the process of gardening.(see Fig. 2)
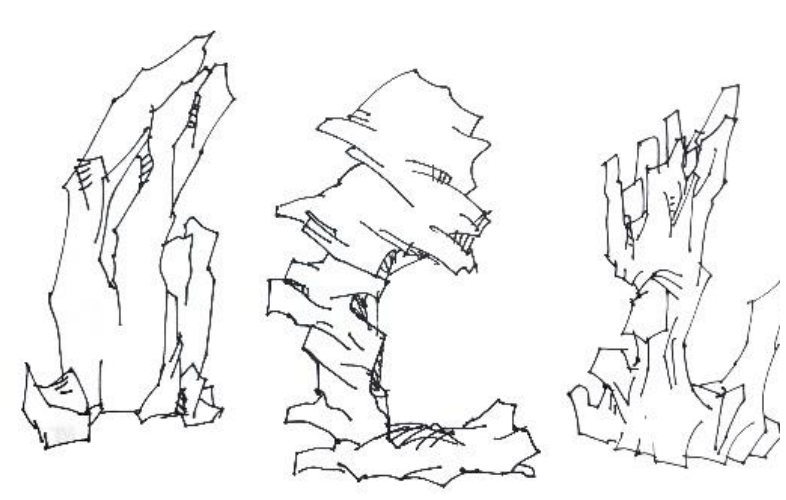

Fig.1 Rockery in Lion Grove Garden 1.

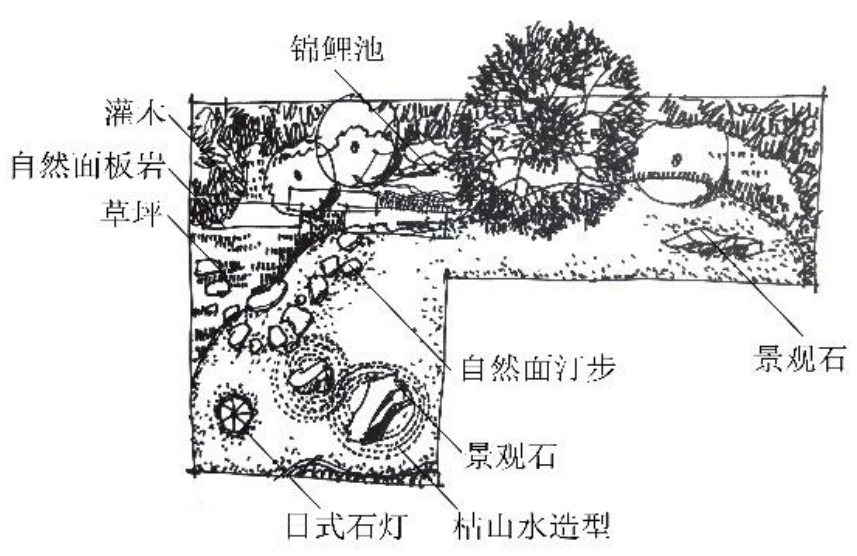

Fig. 2 Plan of Japanese rock garden

\subsection{Chinese Attaching Passion to Shanshui and Japanese Abstraction of Nature}

Since the Emperor Wu of the Han dynasty dismissed all kinds of theoretical schools but only revered Confucian, China had been influenced by the thoughts of Confucianism in a long term. And it goes without saying that gardening is a type of life taste of ancient upper classes. Garden is also called the Garden of Literary and Official. The word "official" represents a famous Chinese idiom that one who is successful in his studies, can get into the official class where there is the highest academic level in ancient China. So the thoughts in garden are from not only the Zen Buddhism, but also the intercommunication and mixture of Confucianism and Daoism. 
More specifically, Confucian thoughts, whose essence is to pursuing achievement, focus on concerning and adjusting the relationship between individual and individual, individual and society, while Taoism, whose essence is to seek after the natural inclinations and interests and happiness in countryside, focus on adjusting the nature to harmonize the relation between individual and nature. These two thoughts are mixed perfectly in Chinese garden. Wherein, Confucian thoughts are mainly presented in orderly and regularly layout, showing the secular of the garden owner. However, trees, rivers, mountains and plants in garden are to show nature, which is the performance of withdraw from worldly affairs in Daoism. Although Zen Buddhism and Daoism are not exactly the same, but as a branch of Chinese religions, Zen Buddhism also pursue a lifestyle that is full of poetic quality and freedom and emphasizes the inner balance. It also pursues the extraordinary state, quietness and content in spirit. It pays attention to a point of particular charm instead of matter, and to mental state instead of objective object, as well as stressing on putting emotion into circumstance. In summary, the Chinese landscape is exactly the result of the mixture of Confucianism, Daoism and Zen, absolutely not only by one thought. However, this kind of mixture has more contradiction. For example, the conflict between concentrate and regular character with active temperament. In a word, being secular means being limitation, while artistic mood means infinity. The spark from the collision of limitation and infinity is exactly where the most important part of Chinese landscape garden lies.

Zen Buddhism influences garden builders, owners and designers by individual intuitive experience and hint, emblem, freehand, as well as the philosophy thought that abides by emptines. When you travel back and forth in the Lion Groven Garden, standing, seating, looking up and down, you can feel the life energy of mountains, rivers, plants, trees, pavilions and bridges and think deeply about the shaping technique of rockery, whose shape should be bent instead of straight and whose meaning lies in emptiness rather than in reality". You can also perceive the philosophy implication that the mountain road twists around each new peak and one way changes and divides many times at last back to one way or the same, and the extremely outward artistic conception in the natural circumstance. It reminds us the verse of Wang Wei," During the moon night, I seat in the quiet bamboo forest. I play the zither for a while and whistle for a while. Nobody with me together but I have the moon as a company." Staying in the quiet and chilly atmosphere far away from common world, feeling cold and loneness and peaceful but free, the hustle and bustle behind the perimeter wall are totally ignored.

Compared with the multi-development of artistic conception and technique of Chinese Zen garden, the development of Japanese Zen garden is pure and stable. Up to now, the amount of reserved Japanese Zen Buddhism gardens is unexpectedly bigger than the Chinese, which has almost disappeared due to political unrest and social vicissitudes in the last several centuries.

With the drawing Five Mountains and Ten Temples introduced into Japan, Japanese Zen Buddhist temples began to imitate and transplant the Buddhist hall of the Song dynasty style and created the unique Japanese Zen Buddhism gardens. They are fond of building gardens, as in their opinion, mountains, rivers and plant gardens can contribute to abdication. Muso Soseki, the great master of Japanese Zen Buddhism during the Muromachi period had in the book Question and Answer in Dream said, "whoever separates landscape gardens and religious practice can't be regarded as the true finally ascetic." Garden becomes obviously an essential part for Zen Buddhism practice. Japanese monks form gardens by using Zen Buddhism stories or prose, such as Saihoji Temple and Shugakuin Imperial Villa. ${ }^{[6]}$ The former belongs to Tenriuji faction of Rinzai school. The latter ranks the biggest plant garden building complex in Japan and is one of the three Japanese imperial household gardens.

Besides, Japanese tea ceremony was also deeply influenced by Zen Buddhism. In the Muromachi period, the development of economy exacerbated competition. Citizens were busy with commercial affairs in a luxurious atmosphere. Some people detested this and began to pursue a quiet and silent ideology. They found a secluded place on outskirts or city, lived in seclusion, enjoyed the delight of simple and unadorned countryside life and seek the easy and comfortable state of mind. Teaism masters, such as Murata Jukō, introduced this kind of beauty awareness into Teaism, making the beauty of quietness and silence spread widely. As is known, Zen and Teaism belong to the same family. As an accessory of Teaism, tea kiosk, originally named as open field, is naturally branded deeply by 
Zen Buddhism. The Japanese ancient book Tea Gathering Collection records," The name of open field shows the lonely state of thatched huts."

As mentioned above, open field in Buddhism means the peaceful and clean state above worldly considerations, which indicates that the spirit of Japanese tea ceremony and Zen are exactly traceable to the same stock. Unlike Chinese Zen gardens, which pay attention to Confucian orders and whose manners are full of natural interest, the artistic conception of Japanese is rather quiet and silent courtyard which stays away from the noise blazes a new trail. The development of Chinese gardens can be seen as natural mountains and trees in city. A lot of Chinese ancient literati gardens were built there due to the garden owners' identities. They have a secluded character but also satisfy the city scale. However, more Japanese gardens choose to escape and isolate themselves from the world. As a result, there is rarely a real sense of gardens in Japanese city.

Japanese rock garden is referred to the representative of Japanese Zen gardens. After the ancient Chinese classical landscape garden was introduced into Japan, they were soon transformed into reduced tiny landscape, in order to fit in the limitation of Japanese geographic condition. Japanese rock garden can often be seen in the Zen cloister which is delicate, tranquil and hidden in depth. In its special environment, there is the symbol of water despite no water, so it got the name of 'dry landscape'. There is no geographic limitation of high mountains, hills, rivers, lakes and creeks, therefore Japanese garden design explores elaboration and delicate and emphasizes on the symbolic meaning of landscape form and the mental feeling. After being thought over and laid out carefully in Japanese rock garden, stone becomes the symbol of mountain range, white sand becomes the symbol of lakes and sea and lines becomes ripples, just like a roll of Shanshui painting which leaves some empty space, building a magnificent scenery with hundreds of cliffs and thousands of gullies in a small space.

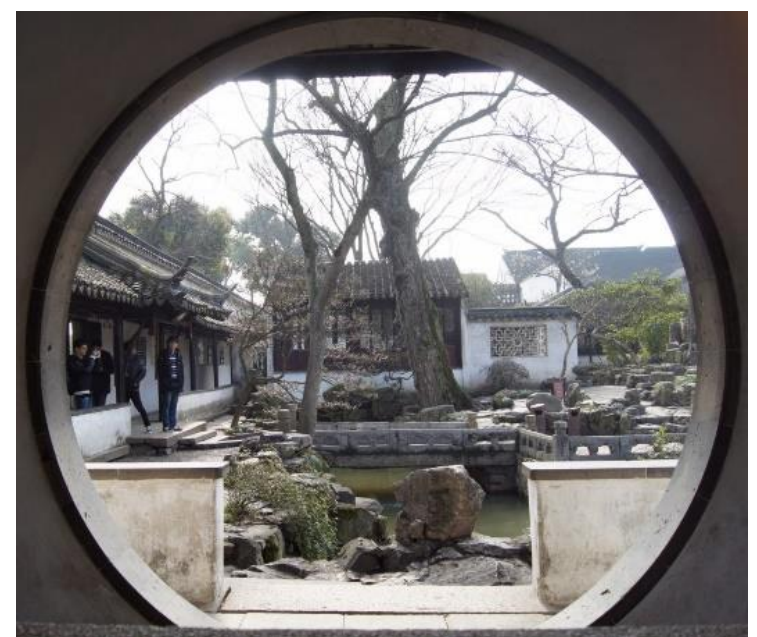

Fig.3 "enframed scenery" in Chinese garden Fig.4 "background scenery" in Japanese rock garden

\subsection{1 "Background Scenery" and "Enframed Scenery"}

In Japanese rock gardens, Macrophanerophytes and arbuscle, which are non-planting and harmonize in color, are frequently used as background scenery to set off main feature in a solemn and respectful atmosphere. The gardens do not stress on depth of field and dynamic effect but three-dimensional visual and static effect. There is no special angle of view or field of vision.In contrast, Chinese are particular about far-reaching conception like Chinese ancient poetry, so they shouldn't have overview in Chinese garden. The graceful landscape is enframed designedly by window frame or cave.

Both kinds of garden are to be appreciated selectively, hence they seem to run in the same groove both in Chinese and Japanese gardening. (see Fig. 3 and 4)

\subsection{2 "To Block" and "To Cover"}


The plant in Japanese garden not only shades the yard and temple, but also combine virtuality and reality through foreground's blocking background. Plants and rocks build a figure-ground relation to express half-virtual and half-real artistic conception.

In Chinese garden, "to cover" is a kind of way of natural element placement, "the landscape changes at every step of visitors," "to place elements at different levels and to construct wood and rock to block and cover one's sight, so man can not get overview." such as Suzhou garden.By this token, both built in different approaches but have equally satisfactory in result. (see Fig. 5)

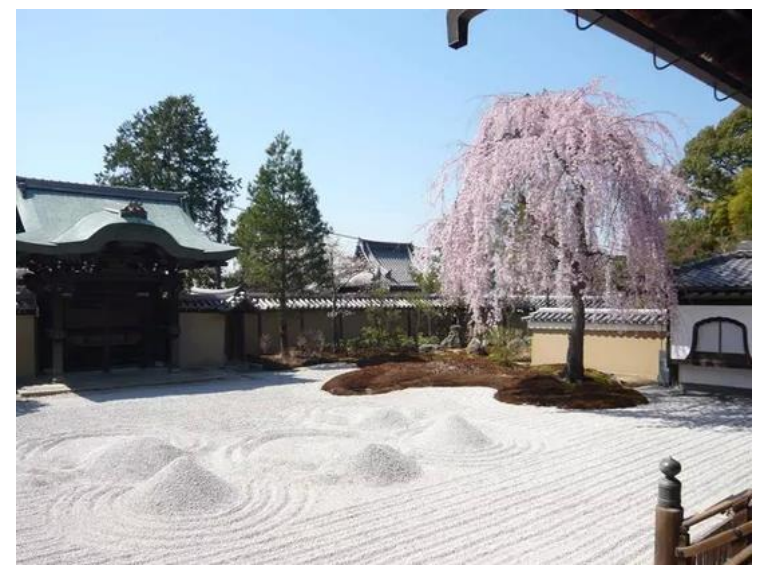

Fig.5 "to block"

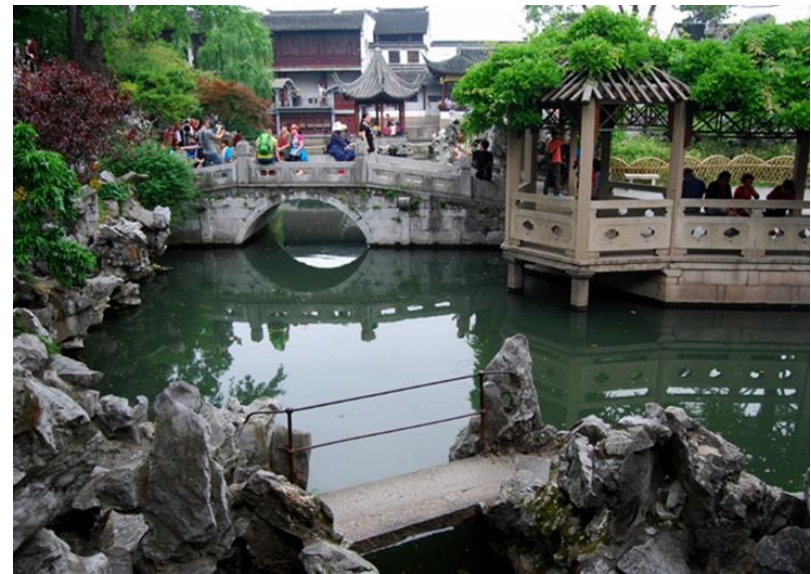

Fig.6 "Landscape changes at every step"

\subsection{3 "To Guide" and "To Correspond"}

In cooperation with main architecture, the plant like Alee-tree in Japanese garden has optical guidance, such as green wall in Ginkaku-ji. Except spatial enclosure and guidance through planting, the correlation between foreground and background vegetation can also guide the vision. For example, plants with bright color and big leaves are used as foreground, and those with dark color and small leaves as background, thus increasing the depth of field and looking more spatially far-reaching. So it is in vertical direction, for example, planting big trees at the foot of the mountain and small trees at the top can increase visual height.

The landscapes in Chinese garden stress on dynamic, blurry, diversity and varity. "To correspond" just belongs to one of them, which lays emphasis on symmetry of axis lines, and corresponding elements locate usually in the middle of axis. If it is in a large-scale scene, the elements always not to be layout at the same axis as general, such as waterside pavilion here and waterfalls there, they stress on the corresponding location and form a natural image. (see Fig. 6)

\subsection{4 "To Continue" and "To Borrow"}

In Japanese garden, evergreen and deciduous plants are matched proportionally to make people's appreciating sentiment. The evergreen, which keeps its color all year round, symbolize the key performance and highlights life and Zen. In the meantime, deciduous plants vary themselves along with time, and this can make an intense person stirs up his or her feelings, like what Kant observed, "where the highest beauty makes people sad".

Chinese garden tents to "borrow". If it is possible, the builders will make advantage of everything with aesthetic value to add color to the landscape, like "breeze brings pleasant cool and the moon brings brightness" in The Humble Administrator's Garden and "breeze and the moon are priceless while water and mountain are sentient" in Canglang Pavilion.

In consideration of limitation of space, Japanese are more inclined to combine categories of plants to enrich garden experience, while Chinese like to utilize as more elements as possible.(see Fig. 7 and 8) 


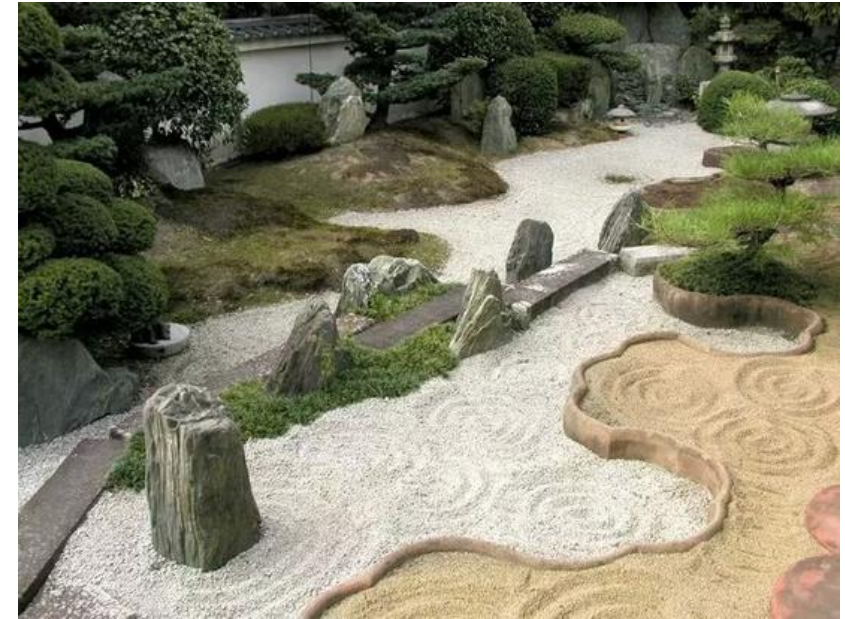

Fig.7 "to continue"

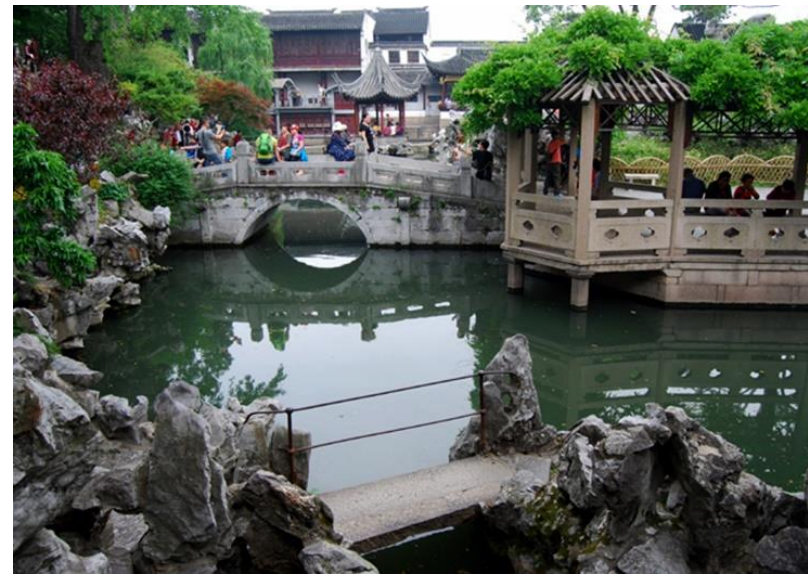

Fig.8 "to borrow"

\section{Figure Source}

Fig. 1 and Fig. 2 from sketches of the authors

Fig.3 from http://blog.sina.com.cnsblog_573cd8380100xf2t.html

Fig.4 from http://www.yijiangshan.cnArticlejingguanshejiribenti_1.html

Fig.5, Fig.7 from http://www.yijiangshan.cnArticlejingguanshejiribenti_1.html

Fig.6, Fig.8 from http://blog.sina.com.cnsblog_4a0080a80102vsfg.html

\section{Conclusion}

In China, garden has a long history, synthesizing many art forms like Shanshui painting, calligraphy, architecture, sculpture, botany and landscape architecture etc. It not only reflects Chinese traditional philosophy, but also contains the essence of Zen. Zen makes it possible for man and nature to communicate through Chinese traditional garden, and creates "empty" in the heart of universe, embodying the suffering of literati and politician that they can not satisfy in real life and the pursuit for "poetically, including the true meaning of life,". Man can comprehend the eternity only through a rock or a plant.

However, while maintaining the gardening conception and spiritual pursuit of Chinese traditional Zen garden, Japanese garden develops a unique garden landscape and spiritual experience, which also belong to one of shining pearls in southeast Asian gardens. From different perspective, the Chinese and Japanese gardens elucidate Zen----one is Chinese Buddhism that sees man's heart directly and think about things with no ponder, and another one is philosophy that explores the universe and penetrate man's disposition. They rooted in the same source and can help us get more ideas about the garden design today, when material resources and nature environment are continue changing.

\section{References}

[1]. Nan Huai-Chin, Chanhua, Fudan University Press, 2004.

[2]. Zhou Weiquan, the history of Chinese classical garden (3rd edition), Tsinghua University Press, 2008.11.

[3]. Qing Pingyong, simple analysis of the influence of zen on chinese classical private garden — quoting Lion Grove Garden as a precedent, Journal of Yichun University, 2009.2, 122

[4]. Mahayana, buddhavatamsaka-mahavaipulya-sutra.

[5]. Zhaoyi, visiting in Lion Grove Garden with Rongxi and Zhitang.

[6]. Zhong Huicheng, first exploration of zen garden, Beijing Forestry University Press, 2007, 89-90.

[7]. Wang Yan, appreciation of the art of Chinese classical garden, Southeast University Press, 2010.9 . 